\title{
A pilot study: lenticule quality of hyperopic small incision lenticule extraction (SMILE) in rabbits
}

Yu Zhao ${ }^{1,2,3+}$, Feng Zhao ${ }^{1,2,3,4+}$, Tian Han $^{1,2,3}$, Jing Zhao ${ }^{1,2,3}$ and Xingtao Zhou ${ }^{1,2,3^{*}}$

\begin{abstract}
Background: To evaluate lenticule surface characteristics of small incision lenticule extraction (SMILE) for hyperopia correction in rabbits.

Methods: The left and right eyes of 8 rabbits were divided into two groups. The right eyes were assigned to a myopia group, and the left eyes to a hyperopia group. The rabbits received SMILE procedures with $+3.00 \mathrm{D}$ and $3.00 \mathrm{D}$ correction for the hyperopia and myopia groups, respectively. Extracted lenticules were examined via scanning electron microscopy. Lenticules from odd-numbered rabbits were accessed with the anterior surface, and lenticules from even-numbered rabbits were observed with the posterior surface. A previously established scoring system was used to evaluate lenticule surface characteristics. Statistical analysis was conducted to compare the scores between the two groups.
\end{abstract}

Results: All procedures were performed successfully, and the lenticules were extracted smoothly. One myopia lenticule that was facing downward was handled failed in preparation for imaging, thus 15 lenticules were ultimately graded. Twelve lenticules exhibited smooth surfaces, and regularly arranged tissue bridges were observed in almost all regions. Three lenticules exhibited a partially rough surface and irregularities affecting more than $10 \%$ of the lenticules ( 2 in the hyperopia group and 1 in the myopia group). Rough lenticules occurred in twice as many lenticules in the hyperopia group compared to the myopia group.

Conclusions: Scan quality of lenticules after SMILE for hyperopia correction is comparable to that of myopia lenticules. The shape of hyperopic lenticule may increase the difficulty of surgical manipulation and result in surface roughness.

Keywords: Hyperopia correction, Lenticule quality, Small incicion lenticule extraction, Refractive surgery

\footnotetext{
* Correspondence: doctzhouxingtao@163.com

${ }^{\dagger}$ Yu Zhao and Feng Zhao contributed equally to this work.

'Department of Ophthalmology, Eye and ENT Hospital of Fudan University, 83 Fenyang Road, Shanghai 200031, PR China

${ }^{2} \mathrm{NHC}$ Key Laboratory of Myopia (Fudan University); Laboratory of Myopia,

Chinese Academy of Medical Sciences, Shanghai, China

Full list of author information is available at the end of the article
}

(c) The Author(s). 2020 Open Access This article is licensed under a Creative Commons Attribution 4.0 International License, which permits use, sharing, adaptation, distribution and reproduction in any medium or format, as long as you give appropriate credit to the original author(s) and the source, provide a link to the Creative Commons licence, and indicate if changes were made. The images or other third party material in this article are included in the article's Creative Commons licence, unless indicated otherwise in a credit line to the material. If material is not included in the article's Creative Commons licence and your intended use is not permitted by statutory regulation or exceeds the permitted use, you will need to obtain permission directly from the copyright holder. To view a copy of this licence, visit http://creativecommons.org/licenses/by/4.0/ The Creative Commons Public Domain Dedication waiver (http://creativecommons.org/publicdomain/zero/1.0/) applies to the data made available in this article, unless otherwise stated in a credit line to the data. 


\section{Synopsis}

The shape of hyperopic lenticule may increase the difficulty of surgical manipulation and result in surface roughness.

\section{Background}

The surgical correction of hyperopia presents a greater challenge than that of myopia for multiple reasons [1,2]. Researchers have studied different refractive techniques for correcting hyperopia, including laser epithelial keratomileusis (LASEK), laser in situ keratomileusis (LASIK), and femtosecond LASIK. These laser platforms have already demonstrated satisfactory predictability and stability of hyperopia correction $[1,3]$.

Small incision lenticule extraction (SMILE) using a femtosecond laser is a well-established surgical procedure for correcting myopia [4]. Thus, the feasibility of using SMILE for hyperopia correction has attracted increased research attention in the field of refraction surgery $[5,6]$. Considering that lenticule surface quality is vital for postoperative optical quality, the purpose of the current study was to evaluate the surface quality of rabbit corneal lenticules extracted during SMILE for hyperopia correction [7].

\section{Methods}

\section{Animals}

Eight healthy adult male New Zealand rabbits (provided by the Department of Animal affiliated with Shanghai Medical College of Fudan University) weighing between 2.5 and $3.0 \mathrm{~kg}$ and free of anterior segmental diseases were used in the study. The left eyes of all rabbits were assigned to a hyperopia group, and the right eyes to a myopia group. All the experimental and animal handling procedures met the tenets of the Association for Research in Vision and Ophthalmology Statement for the Use of Animals in Ophthalmic and Vision Research, and adhered to the requirements of the Animal Research and Ethics Committee of the Eye and ENT Hospital, Fudan University, Shanghai, China who also approved this study.

\section{Surgical technique}

All surgical procedures were performed by the same surgeon under general anesthesia with an intramuscular injection of ketamine hydrochloride $(50 \mathrm{mg} / \mathrm{kg})$ and xylazil $(5 \mathrm{mg} / \mathrm{kg}$ ). The VisuMax femtosecond laser system (Carl Zeiss Meditec AG, Berlin, Germany) was used to perform SMILE and the same surgeon (XZ) performed all procedures. Rabbits were anesthetized via the intramuscular injection of ketamine hydrochloride $(125 \mathrm{mg} / \mathrm{kg})$ and topical anesthesia with $0.4 \%$ oxybuprocaine hydrochloride eye drops. The femtosecond laser was set at a repetition rate of $500 \mathrm{kHz}$ and a pulse energy of $130 \mathrm{~nJ}$.
A small (S) size contact glass was used in all myopia cases and a medium (M) size was applied for hyperopia correction. The suction ring was activated to fix the eyeball prior to laser scanning. A corneal cap of $7.5 \mathrm{~mm}$ with a thickness of $110 \mu \mathrm{m}$ was applied. Lenticule diameter was set as $5.5 \mathrm{~mm}$. The length of the side cut was set to a 2-mm angle at the superior 12-o'clock position. The intended hyperopia and myopia correction was + 3.00 and -3.00 diopters spheres, respectively. The central minimum lenticule thickness of hyperopia lenticule was $25 \mu \mathrm{m}$, and a transition zone was $0.2 \mathrm{~mm}$. After scanning was completed, the refractive lenticule was separated and removed through the side cut incision smoothly. The rabbits were kept for further studies (wound healing response).

\section{Scanning Electron microscopy}

All lenticules were immediately cleaned with normal saline and immersed in $1.25 \%$ glutaraldehyde at $4{ }^{\circ} \mathrm{C}$ for 2 $\mathrm{h}$. The specimens were treated with osmium acid before being dehydrated in a series of graded ethanol baths and then critical point dried. In each group, specimens from the odd-numbered rabbits were facing upward, and those from the even-numbered rabbits were facing downward. The samples were then mounted on scanning electron microscopy (SEM) stubs, sputter coated, and examined with via SEM (Hitachi S-SU8010).

\section{Surface quality analysis}

Specimens were graded and scored by two observers ( $\mathrm{YZ}$ and FZ) in a blinded fashion. The surface quality of the lenticules was assessed on the basis of the electron

Table 1 Criteria for evaluating surface characteristics

\begin{tabular}{lll}
\hline Criterion and Magnification & Appearance & Scores \\
\hline A Surface relief $\times 100$ & Very smooth & 4 \\
& Smooth & 3 \\
& Rough & 2 \\
& Very rough & 1 \\
B Regularity of surface structure $\times 300$ & Completely regular & 4 \\
& Almost Regular & 3 \\
& Partially regular & 2 \\
& Not regular & 1 \\
& $<10 \%$ of cut surface & 4 \\
C Portion of surface irregular $\times 300$ & $11-25 \%$ of cut surface & 3 \\
& $26-50 \%$ of cut surface & 2 \\
& $>50 \%$ of cut surface & 1 \\
& No irregularities & 4 \\
& Peripheral only & 3 \\
& Large region & 2 \\
& All over & 1 \\
\hline
\end{tabular}


micrographs at $100 \times$ and $300 \times$ magnification. A scoring system that we have previously described [8] was used to evaluate surface characteristics of the lenticules. Four criteria were utilized to assess surface morphology: surface relief, regularity of the surface structure, the proportion of the surface that was irregular, and the position of the irregular area (Table 1). For surface relief, the entire lenticule was evaluated at 100× magnification. All other criteria were assessed at $300 \times$ magnification. A maximum of 16 points could be assigned to each lenticule.

\section{Statistical analysis}

First, the normality of the paired difference was tested via the Kolmogorow-Smirnow test. Then, the paired $t$ test or the Wilcoxon matched-pairs signed-ranks test was used assess differences between groups. All analyses were performed in SPSS version 19.0 (SPSS Inc., Chicago, IL, USA), and $p<0.05$ was considered statistically significant.

\section{Results}

All surgical procedures were performed successfully and the lenticules were extracted smoothly. One myopia lenticule that was facing downward was handled failed in preparation for imaging, thus 15 lenticules were ultimately graded.

On the whole, 12 lenticules showed smooth surfaces at $100 \times$ magnification. At $300 \times$ magnification, regularly arranged tissue bridges were observed in more than $75 \%$ of the entire region-areas of disordered tissue bridges constituted less than $25 \%$ of the total area and were distributed peripherally. A total of 13 points was assigned to 11 specimens and 12 points was assigned to the other specimen.

Three lenticules exhibited with partial rough surfaces. In 1 hyperopia lenticule facing downward, less than $25 \%$ of the total area was irregular. In 1 hyperopia lenticule facing upward and 1 myopia lenticule facing downward, more than $25 \%$ of the total area was heterogeneous with irregularities distributed over a large region.

The mean scores of anterior surfaces were $11.75 \pm 2.50$ for the hyperopia group and $12.75 \pm 0.50$ for the myopia group (Table 2). For the posterior surfaces, the average scores were $12.25 \pm 1.50$ for the hyperopia group and $11.33 \pm 2.89$ for the myopia group (Table 2). There were no significant differences between the lenticule surface scores of the two groups ( $p=0.655$ for the anterior surface and $p=0.317$ for the posterior surface). Representative images of the lenticules are shown in (Figs. 1, 2, 3 and 4).

\section{Discussion}

Creating a lenticule with good surface quality is essential in SMILE, because it has been proved that lenticule quality is significantly correlated with the incidence of vision-threatening complications and refractive outcomes [9-12]. Therefore, it is important to guarantee lenticule surface quality in SMILE for hyperopia correction. In the current study, we evaluated lenticule surface characteristics after SMILE for hyperopia correction in rabbits for the first time [13].

Tissue bridges were distributed evenly in most areas of the lenticules. It has been reported that tissue bridges were the main entity for surface irregularities on the

Table 2 Score results for lenticules in two groups

\begin{tabular}{|c|c|c|c|c|c|c|c|c|c|}
\hline Surface & Group & Sample & Surface Relief & Regularity of Surface & Portion of Surface Irregular & Position of the Irregular & Score & Average & SD \\
\hline \multirow[t]{8}{*}{ Anterior } & \multirow[t]{4}{*}{ Hyperopia } & $1 \mathrm{~L}$ & 3 & 3 & 4 & 3 & 13 & \multirow[t]{4}{*}{11.75} & \multirow[t]{4}{*}{2.50} \\
\hline & & $3 L$ & 2 & 2 & 2 & 2 & 8 & & \\
\hline & & $5 \mathrm{~L}$ & 3 & 3 & 4 & 3 & 13 & & \\
\hline & & $7 \mathrm{~L}$ & 3 & 3 & 4 & 3 & 13 & & \\
\hline & \multirow[t]{4}{*}{ Myopia } & $1 \mathrm{R}$ & 3 & 3 & 4 & 3 & 13 & \multirow[t]{4}{*}{12.75} & \multirow[t]{4}{*}{0.50} \\
\hline & & $3 R$ & 3 & 3 & 4 & 3 & 13 & & \\
\hline & & $5 R$ & 3 & 3 & 3 & 3 & 12 & & \\
\hline & & $7 \mathrm{R}$ & 3 & 3 & 4 & 3 & 13 & & \\
\hline \multirow[t]{7}{*}{ Posterior } & \multirow[t]{4}{*}{ Hyperopia } & $2 \mathrm{~L}$ & 2 & 2 & 3 & 3 & 10 & \multirow[t]{4}{*}{12.25} & \multirow[t]{4}{*}{1.50} \\
\hline & & $4 \mathrm{~L}$ & 3 & 3 & 4 & 3 & 13 & & \\
\hline & & $6 \mathrm{~L}$ & 3 & 3 & 4 & 3 & 13 & & \\
\hline & & $8 \mathrm{~L}$ & 3 & 3 & 4 & 3 & 13 & & \\
\hline & \multirow[t]{3}{*}{ Myopia } & $2 \mathrm{R}$ & 2 & 2 & 2 & 2 & 8 & \multirow[t]{3}{*}{11.33} & \multirow[t]{3}{*}{2.89} \\
\hline & & $6 \mathrm{R}$ & 3 & 3 & 4 & 3 & 13 & & \\
\hline & & $8 R$ & 3 & 3 & 4 & 3 & 13 & & \\
\hline
\end{tabular}

SD standard deviation

$1 \mathrm{~L}$ means lenticule from the left eye of the rabbit numbered 1 and so on 

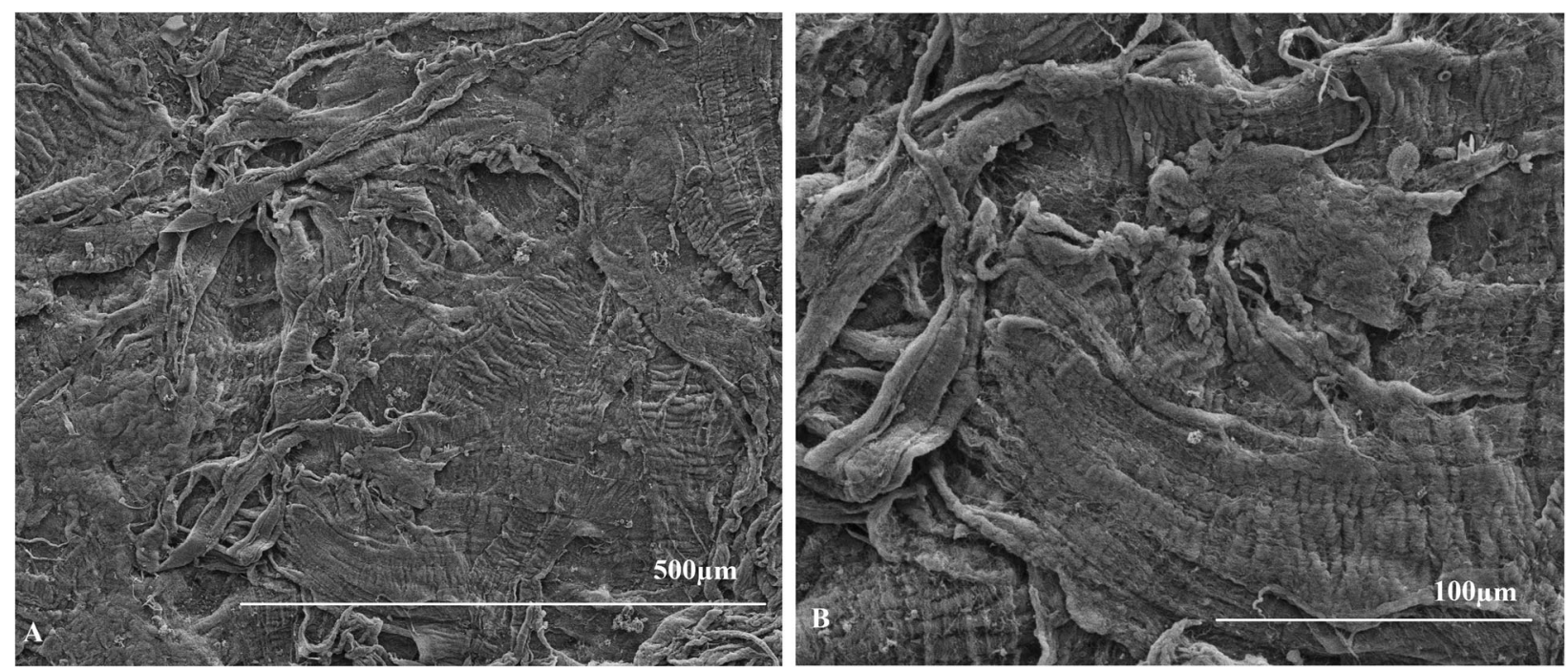

Fig. 1 Images of anterior surface of hyperopia lenticule from the left eye of the rabbit numbered 3 at 100x magnification (a) and at $300 \times$ magnification (b). With example of the score result of 8 points

corneal lenticule surface [14]. It was described as residual fibers between the interfaces after completion of laser cuts. Laser cutting, as well as surgical manipulation, could affect the arrangement of tissue bridges. In the current study, although the laser settings were exactly the same as those used in the previous study evaluating human lenticules, tissue bridges in rabbit lenticules were longer and looser compared to those of human lenticules [8]. There are two potential reasons for this. One is that the structure of corneal collagen fibers in rabbits may differ from that of humans. Another possibility is that the rabbits had bad coordination during the operation and required more surgical dissection, which may have affect the surface quality and cause the roughness.

The lenticules exhibited comparable surface characteristics in both of the groups in the study, and the central and periphery regions of the posterior surfaces of the hyperopia lenticules exhibited similar arranged tissue bridges. However, rough lenticules occurred in twice as many lenticules in the hyperopia group compared to the myopia group, and the results implied that the hyperopia lenticule may be more likely to presented with
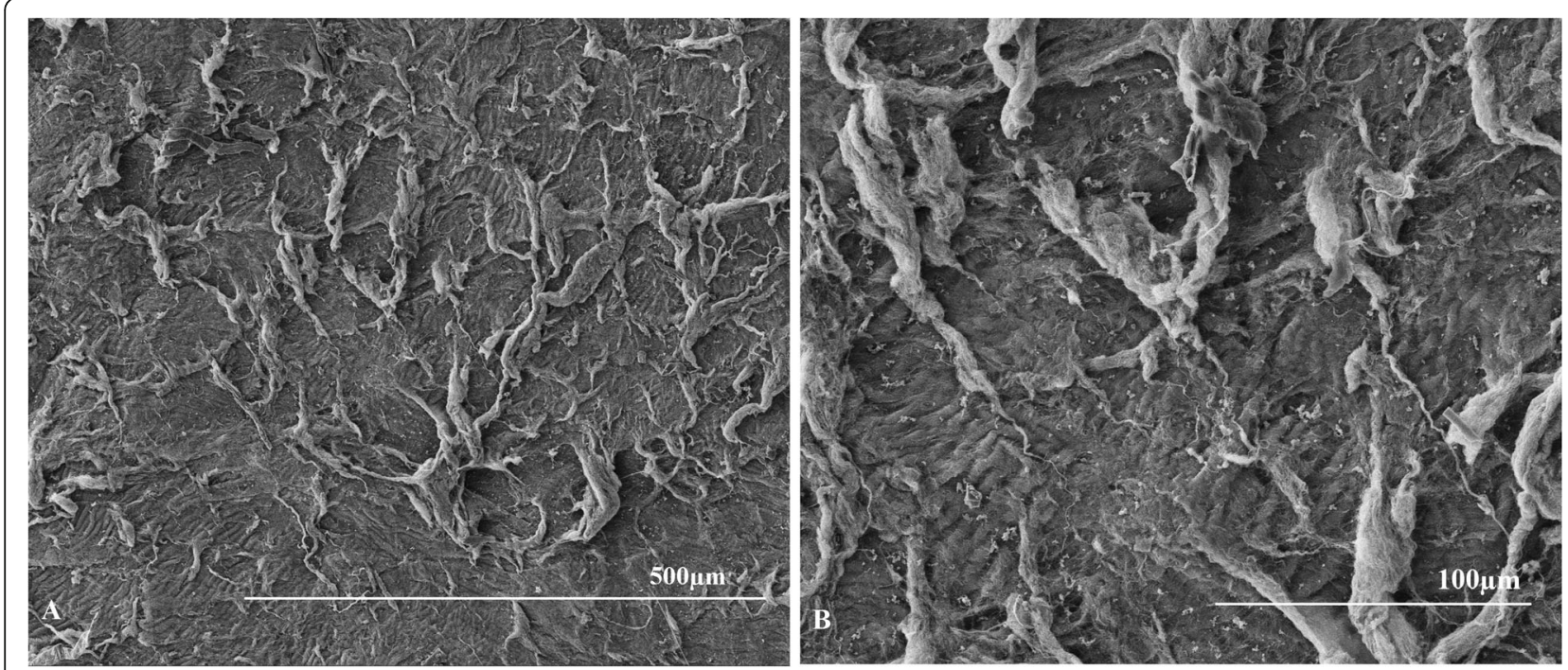

Fig. 2 Images of anterior surface of hyperopia lenticule from the left eye of the rabbit numbered 7 at 100x magnification (a) and at $300 \times$ magnification (b). With example of the score result of 13 points 

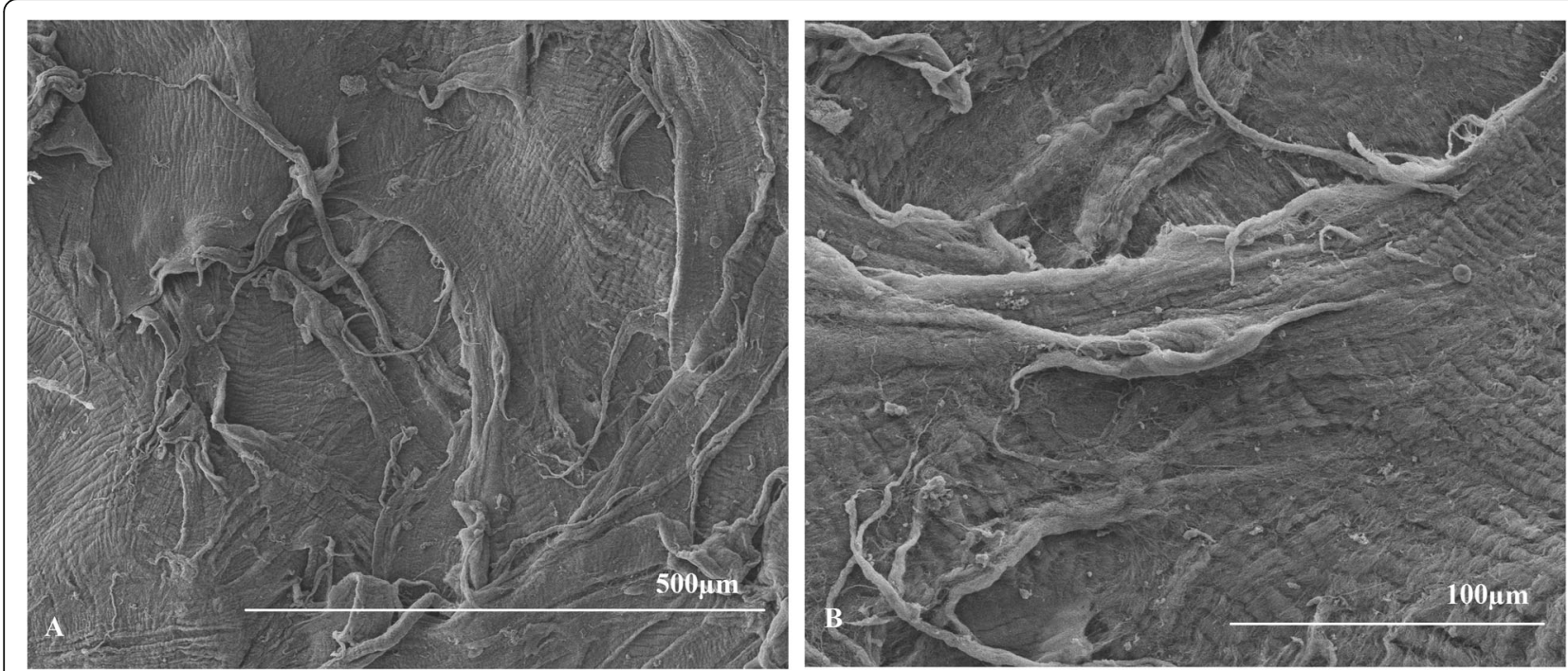

Fig. 3 Images of posterior surface of hyperopia lenticule from the left eye of the rabbit numbered 2 at $100 \times$ magnification (a) and at $300 \times$ magnification (b). With example of the score result of 10 points

roughness. With regard to the treatment of hyperopia, it has been reported that lenticule shape was thicker in the periphery and thinner in the center $[15,16]$. This may increase the difficulty of surgical manipulation and result in surface roughness. To reduce operative difficulty, the minimal central thickness of hyperopic lenticule was limited to $25 \mu \mathrm{m}$ in the current study. Also, the surgeon had extensive experience in the performance of SMILE and performed the procedure gently, and tried his utmost not to induce surface roughness artificially.
Notably however, among the 3 cases that exhibited partially rough surfaces, in 2 cases it was related to the posterior surface and in only 1 case it was related to the anterior surface The results suggested that dissection between the lenticule-stromal bed interface could be more difficult than dissection at the cap-lenticule interface: the anterior surface can be dissected under the cap smoothly, but for the posterior surface, dissection was done more slowly and involved repetition action because the lenticule was thin and unfixed. This emphasizes the
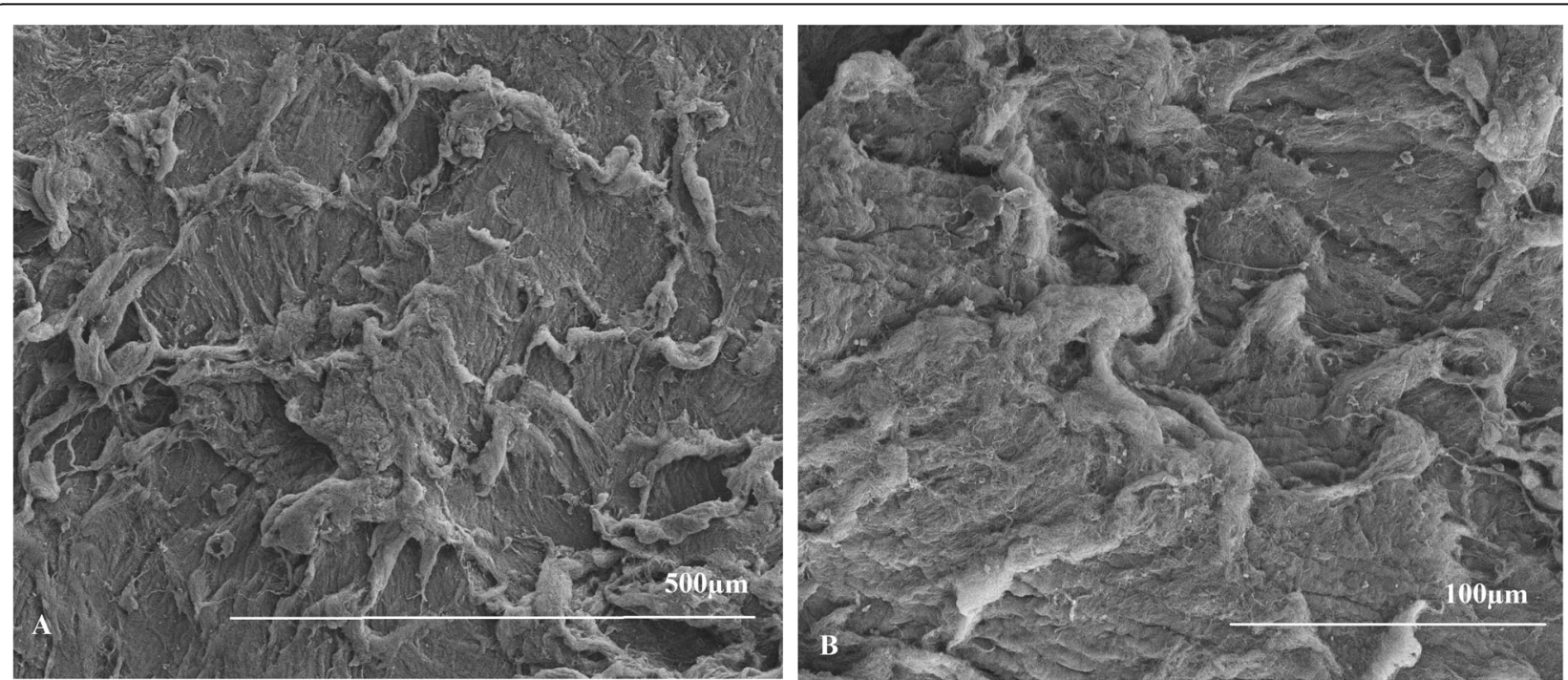

Fig. 4 Images of posterior surface of myopia lenticule from the right eye of the rabbit numbered 2 at $100 \times$ magnification (a) and at $300 \times$ magnification (b). With example of the score result of 8 points 
importance of good cooperation and careful surgical manipulation during the procedure, for both hyperopia and myopia correction [17].

Visible cavitation holes were absent in all lenticules except 1 in the myopia group that exhibited a few cavitation holes on the anterior surface. Cavitation holes are gas bubbles formed during the vaporization of the corneal tissue, and they affect scanning quality [14]. The scanning quality of the both surfaces of the lenticules was comparable in the two groups. The working principle of the femtosecond laser may explain this finding. The femtosecond laser is a near-infrared laser that produces ultra-short pulses of light [18]. In the nonthermal ablation process that is achieved via corneal photodisruption, a plasma state develops with optical breakdown, and some cavitation gas bubbles are formed. A series of bubbles is created resulting in separating of the corneal tissue at a precise depth [19]. The system used in the procedure could accomplish homogeneous cut in most cases. However, in some unexpected cases, for example, corneal edema or eye rotation during the laser scanning, may affect the homogeneity of laser cutting and result in cavitation holes.

Previous studies had investigated the corneal surface characteristics in myopia correction during SMILE, and reported that pulse energy and laser frequency are two foremost parameters influencing scanning quality [20]. Heichel [14] firstly reported scoring of lenticule surface quality in porcine corneas using the original VisuMax femtosecond laser system with a repetition rate of 200 $\mathrm{kHz}$ and a pulse energy of $185 \mathrm{~nJ}$. Although lenticules of predictable surface quality were created in the procedure, the results suggested that laser settings should be improved. Kunert [10] evaluated lenticule surface characteristics with a fixed repetition rate of $200 \mathrm{kHz}$ and different energy levels (150, 180, and $195 \mathrm{~nJ})$. The highest surface regularity score was achieved using the lowest pulse energy, presenting that lower pulse energy facilitates a smoother cut surface. Furthermore, smoother lenticule surfaces were reported observed using a higher frequency laser $[8,21]$.

Based on the aforementioned investigations, a new generation VisuMax laser with settings of a $500 \mathrm{kHz}$ repetition rate and a pulse energy of $130 \mathrm{~nJ}$ was investigated. Researchers studied the scan quality of corneal lenticules in the context of myopia treatment using the new laser system, and found that both sides of the lenticules exhibited smooth surfaces [21]. Therefore, in the current study, the exact same laser settings were used to perform hyperopia correction in SMILE, and enabled homogeneous cutting.

The current study had some limitations, the foremost being the small number of specimens involved. Also, while precautions were taken during preparation for imaging, scratches and grooves may have been generated. Lastly, the refractive outcomes, were not evaluated in the current study, need further investigations.

\section{Conclusions}

In conclusion, scan quality of lenticules after SMILE for hyperopia correction is comparable to that of myopia lenticules. The shape of hyperopic lenticule may increase the difficulty of surgical manipulation and result in surface roughness.

\section{Abbreviations \\ SMILE: Small incision lenticule extraction; LASEK: Laser epithelial keratomileusis; LASIK: Laser in situ keratomileusis; SEM: Scanning electron microscopy}

\section{Acknowledgements \\ None.}

\section{Authors' contributions}

Study concept and design (YZ, FZ, XZ); conduct the experiment (YZ, FZ, TH, $J Z, X Z)$; data collection (YZ, FZ, XZ); drafting of the manuscript (YZ); critical revision of the manuscript (XZ); supervision (XZ). All authors read and approved the final manuscript.

\section{Funding}

1. The National Natural Science Foundation of China (Grant No.81770955)

2. Project of Shanghai Science and Technology (Grant No.17411950200 \&17411950201)

3. Joint Research Project of New Frontier Technology in Municipal Hospitals (Grant No. SHDC12018103)

\section{Availability of data and materials}

All data used and analyzed in this study are available upon request from the first author; Yu Zhao.

\section{Ethics approval and consent to participate}

All the experimental and animal handling procedures met the tenets of the Association for Research in Vision and Ophthalmology Statement for the Use of Animals in Ophthalmic and Vision Research. Ethics Committee of the Eye and ENT Hospital, Fudan University, Shanghai, China also approved this study.

\section{Consent for publication}

Not applicable.

\section{Competing interests}

The authors declare that they have no competing interests.

\section{Author details}

'Department of Ophthalmology, Eye and ENT Hospital of Fudan University, 83 Fenyang Road, Shanghai 200031, PR China. ${ }^{2}$ NHC Key Laboratory of Myopia (Fudan University); Laboratory of Myopia, Chinese Academy of Medical Sciences, Shanghai, China. ${ }^{3}$ Shanghai Research Center of Ophthalmology and Optometry, Shanghai, China. ${ }^{4}$ Department of Ophthalmology, Shuguang Hospital Affiliated to Shanghai University of Traditional Chinese Medicine, Shanghai, China.

Received: 12 December 2018 Accepted: 13 April 2020

Published online: 19 April 2020

\section{References}

1. Lee BS. Accuracy and stability of hyperopic treatments. Curr Opin Ophthalmol. 2014;25(4):281-5. https://doi.org/10.1097/ICU.0000000000000066.

2. Jaycock PD, O'Brart DP, Rajan MS, Marshall J. 5-year follow-up of LASIK for hyperopia. Ophthalmology. 2005;112(2):191-9. https://doi.org/10.1016/j. ophtha.2004.09.017. 
3. Kanellopoulos AJ. Topography-guided hyperopic and hyperopic astigmatism femtosecond laser-assisted LASIK: long-term experience with the $400 \mathrm{~Hz}$ eye-Q excimer platform. Clin Ophthalmol. 2012;6:895-901. https://doi.org/10.2147/OPTH.S23573.

4. Pradhan KR, Reinstein DZ, Carp GI, Archer TJ, Gobbe M, Dhungana P. Quality control outcomes analysis of small-incision lenticule extraction for myopia by a novice surgeon at the first refractive surgery unit in Nepal during the first 2 years of operation. J Cataract Refract Surg. 2016;42(2):267-74. https:// doi.org/10.1016/j.jcrs.2015.09.026.

5. Reinstein DZ, Pradhan KR, Carp GI, Archer TJ, Gobbe M, Sekundo W, et al. Small Incision Lenticule Extraction (SMILE) for Hyperopia: Optical Zone Centration. J Refract Surg. 2017;33(3):150-6. https://doi.org/10.3928/ 1081597X-20161220-01.

6. Reinstein DZ, Pradhan KR, Carp Gl, Archer TJ, Gobbe M, Sekundo W, et al. Small Incision Lenticule Extraction (SMILE) for Hyperopia: Optical Zone Diameter and Spherical Aberration Induction. J Refract Surg. 2017;33(6):3706. https://doi.org/10.3928/1081597X-20170331-01.

7. Vinciguerra P, Azzolini M, Radice P, Sborgia M, De Molfetta V. A method for examining surface and interface irregularities after photorefractive keratectomy and laser in situ keratomileusis: predictor of optical and functional outcomes. J Refract Surg. 1998;14(2 Suppl):S204-6.

8. Zhao Y, Li M, Sun L, Zhao J, Chen Y, Zhou X. Lenticule Quality After Continuous Curvilinear Lenticulerrhexis in SMILE Evaluated With Scanning Electron Microscopy. J Refract Surg. 2015;31(11):732-5. https://doi.org/10. 3928/1081597X-20151029-01.

9. Sarayba MA, Ignacio TS, Binder PS, Tran DB. Comparative study of stromal bed quality by using mechanical, IntraLase femtosecond laser 15- and 30kHz microkeratomes. Cornea. 2007;26(4):446-51. https://doi.org/10.1097/ICO. Ob013e318033e7cc.

10. Kunert KS, Blum M, Duncker GI, Sietmann R, Heichel J. Surface quality of human corneal lenticules after femtosecond laser surgery for myopia comparing different laser parameters. Graefe's Arch Clin Exp Ophthalmol. 2011;249(9):1417-24. https://doi.org/10.1007/s00417-010-1578-4.

11. Wilhelm FW, Giessmann T, Hanschke R, Duncker Gl, Wilhelm LH. Cut edges and surface characteristics produced by different microkeratomes. J Refract Surg. 2000;16(6):690-700.

12. Damgaard IB, Riau AK, Liu YC, Tey ML, Yam GH, Mehta JS. Reshaping and Customization of SMILE-Derived Biological Lenticules for Intrastromal Implantation. Invest Ophthalmol Visual Sci. 2018;59(6):2555-63. https://doi. org/10.1167/iovs.17-23427.

13. Qin S, Zheng S, Qi B, Guo R, Hou G. Decellularized human stromal Lenticules combine with corneal epithelial-like cells: a new resource for corneal tissue engineering. Stem Cells Int. 2019;4252514. https://doi.org/10. 1155/2019/4252514

14. Heichel J, Blum M, Duncker Gl, Sietmann R, Kunert KS. Surface quality of porcine corneal lenticules after Femtosecond Lenticule Extraction. Ophthal Res. 2011;46(2):107-12. https://doi.org/10.1159/000323814.

15. Sekundo W, Reinstein DZ, Blum M. Improved lenticule shape for hyperopic femtosecond lenticule extraction (ReLEx FLEx): a pilot study. Lasers Med Sci. 2016;31(4):659-64. https://doi.org/10.1007/s10103-016-1902-2.

16. Zhao J, Miao H, Han T, Shen Y, Zhao Y, Sun L, et al. A Pilot Study of SMILE for Hyperopia: Corneal Morphology and Surface Characteristics of Concave Lenticules in Human Donor Eyes. J Refract Surg. 2016;32(10):713-6. https:// doi.org/10.3928/1081597X-20160718-01.

17. Liu YC, Pujara T, Mehta JS. New instruments for lenticule extraction in small incision lenticule extraction (SMILE). PloS one. 2014;9(12):e113774. https:// doi.org/10.1371/journal.pone.0113774.

18. Holzer MP, Rabsilber TM, Auffarth GU. Femtosecond laser-assisted corneal flap cuts: morphology, accuracy, and histopathology. Invest Ophthalmol Visual Sci. 2006;47(7):2828-31. https://doi.org/10.1167/iovs.05-1123.

19. Sekundo W, Kunert KS, Blum M. Small incision corneal refractive surgery using the small incision lenticule extraction (SMILE) procedure for the correction of myopia and myopic astigmatism: results of a 6 month prospective study. Br J Ophthalmol. 2011;95(3):335-9. https://doi.org/10. 1136/bjo.2009.174284.

20. Lombardo M, De Santo MP, Lombardo G, Schiano Lomoriello D, Desiderio $G$, Ducoli $P$, et al. Surface quality of femtosecond dissected posterior human corneal stroma investigated with atomic force microscopy. Cornea. 2012; 31(12):1369-75. https://doi.org/10.1097/ICO.0b013e31823f774C.

21. Ziebarth NM, Lorenzo MA, Chow J, Cabot F, Spooner GJ, Dishler J, et al. Surface quality of human corneal lenticules after SMILE assessed using environmental scanning electron microscopy. J Refract Surg. 2014;30(6):38893. https://doi.org/10.3928/1081597X-20140513-01.

\section{Publisher's Note}

Springer Nature remains neutral with regard to jurisdictional claims in published maps and institutional affiliations.
Ready to submit your research? Choose BMC and benefit from:

- fast, convenient online submission

- thorough peer review by experienced researchers in your field

- rapid publication on acceptance

- support for research data, including large and complex data types

- gold Open Access which fosters wider collaboration and increased citations

- maximum visibility for your research: over $100 \mathrm{M}$ website views per year

At $\mathrm{BMC}$, research is always in progress.

Learn more biomedcentral.com/submissions 